\title{
Satisfação de clientes com o atendimento bancário
}

\author{
Customer satisfaction with bank care \\ Satisfacción del cliente con el servicio bancário
}

Recebido: 26/07/2021 | Revisado: 31/07/2021 | Aceito: 25/08/2021 | Publicado: 27/08/2021

\author{
Euder Ramos Lima \\ ORCID: https://orcid.org/0000-0002-5746-4688 \\ Universidade do Estado da Bahia, Brasil \\ E-mail: rlima.euder@gmail.com \\ Terezinha Camargo Magalhães \\ ORCID: https://orcid.org/0000-0002-6369-309X \\ Universidade do Estado da Bahia, Brasil \\ E-mail: tecamargo10@gmail.com
}

\begin{abstract}
Resumo
A satisfação do cliente pode ser entendida como a sensação de contentamento ou decepção em relação à expectativa criada para determinado produto ou serviço. O objetivo deste estudo foi compreender a satisfação dos clientes com o atendimento disponibilizado pelo banco "X" localizado numa cidade do Interior da Bahia. Utilizou-se a abordagem qualitativa interpretativa do tipo pesquisa de campo, tendo como universo clientes de uma agência do banco "X" localizado numa cidade do Interior da Bahia, tendo sido entrevistados 13 clientes, fazendo-o através de perguntas abertas para coleta mais precisa e completa de dados. Com as respostas das entrevistas, foi realizada uma análise de conteúdo dos dados na modalidade temática. Os resultados mostram que os clientes são satisfeitos com a qualidade dos serviços prestados diretamente pelos funcionários além dos serviços disponibilizados em canais alternativos como o Internet Banking e o atendimento pelo Celular. Num contexto geral o estudo concluiu que os entrevistados mostraram-se satisfeitos ante os serviços dispensados pela Agência bancária.
\end{abstract}

Palavras-chave: Atendimento bancário; Satisfação do cliente; Serviços.

\begin{abstract}
Customer satisfaction can be understood as the feeling of contentment or disappointment over the expectation created for a given product or service. The objective of this study was to understand customer satisfaction with the service provided by the bank "X" located in a city of the Interior of Bahia. We used the qualitative interpretive approach of the field research type, having as clients of an agency of the " $\mathrm{X}$ " bank located in a city of the Interior of Bahia, having been interviewed 13 clients, doing it through open questions for more precise collection and complete data. With the answers of the interviews, a content analysis of the data in the thematic modality was performed. The results show that customers are satisfied with the quality of the services provided directly by the employees besides the services offered in alternative channels such as Internet Banking and the service by the Cellular. In a general context the study concluded that the interviewees were satisfied with the services provided by the Banking Agency.
\end{abstract}

Keywords: Banking service; Customer satisfaction; Services.

\section{Resumen}

La satisfacción del cliente puede entenderse como el sentimiento de satisfacción o decepción en relación con la expectativa creada por un determinado producto o servicio. El objetivo de este estudio fue conocer la satisfacción del cliente con el servicio brindado por el banco " $X$ " ubicado en una ciudad del interior de Bahía. Se utilizó un enfoque de investigación de campo interpretativa cualitativa, teniendo como universo a los clientes de una sucursal del banco "X" ubicada en una ciudad del interior de Bahía, se entrevistó a 13 clientes mediante preguntas abiertas para una recopilación más precisa. datos. Con las respuestas de las entrevistas, se realizó un análisis de contenido de los datos en la modalidad temática. Los resultados muestran que los clientes están satisfechos con la calidad de los servicios prestados directamente por los empleados, además de los servicios prestados a través de canales alternativos como la Banca por Internet y el servicio de telefonía celular. En un contexto general, el estudio concluyó que los encuestados estaban satisfechos con los servicios prestados por la sucursal bancaria.

Palabras clave: Servicio bancario; Satisfacción del cliente; Servicios.

\section{Introdução}

Priorizar a satisfação de seus clientes já configura um dos principais meios para auxiliar no crescimento e na maximização dos resultados de um negócio, necessitando, portanto, administrarem-se os seus consumidores como se faz com 
os seus ativos financeiros (Kotler, 2003). Para tanto, uma empresa que preze pelo seu crescimento e entrega de resultados, deve buscar manter os seus clientes num grau de satisfação superior ao que os seus concorrentes oferecem, empenhando-se para torná-los fascinados e atraídos pelos produtos ou serviços comercializados. Ademais, deve entender e identificar os aspectos relevantes que modificam o seu mercado-alvo, bem como os seus fornecedores e concorrentes (Kotler, 2003, Las Casas, 2006).

Em razão do recente avanço da tecnologia no setor bancário, com a possibilidade de realização de transações na internet e em celulares, os últimos estudos sobre satisfação estão, em sua maioria, voltados ao público que se beneficia dessas tecnologias, a exemplo de Souza et al. (2018) que investigaram como o avanço do Internet Banking está modificando a satisfação dos clientes bancários e Mattana (2017), em seu estudo, procurou avaliar os índices de satisfação do atendimento digital ofertado a clientes bancários.

Contudo, os estudos existentes na literatura que buscaram compreender o nível de satisfação dos clientes do setor bancário, são de natureza quantitativa, a exemplo de Dauda e Lee (2016) que realizaram um estudo para avaliar a satisfação dos clientes sobre os serviços bancários na Nigéria, foram investigados 1.245 clientes de bancos. $\mathrm{O}$ estudo conclui que os clientes nigerianos valorizam mais o tempo de espera e o custo da transação, mostrando que as dimensões de conveniência e custo têm efeito forte e direto na qualidade do serviço. Santana, Ribeiro e Silva (2017) que, para mensurar, fizeram uso de 150 questionários num total de 370 clientes existentes numa cooperativa de crédito, e Chieira (2013) que, num outro estudo, aplicou 400 questionários com a finalidade de reconhecer os elementos que contribuem para a satisfação de clientes com o seu principal banco.

\section{Cliente}

Conforme Moura (1997, p. 57), clientes “são todos aqueles que adquirem e fazem uso dos produtos das empresas”. Já Las Casas (2011, p. 181), em um pensamento semelhante, classifica o cliente com uma "pessoa ou organização que tem um papel na consumação de uma transação com o vendedor ou entidade". Sendo assim, podemos entender que qualquer indivíduo que contrai produtos e serviços fornecidos por uma organização pode ser denominado cliente.

Em consonância com o entendimento de Moura (1997), Castelli (2003) afirma que qualquer indivíduo que realiza tarefas e passa-as adiante é chamado de fornecedores, e os que adquirem são intitulados clientes. Ele ainda assinala que os clientes podem ser tanto externos, quanto internos. Com o surgimento e a popularização da internet, os clientes de hoje detêm mais informações acerca de produtos e fornecedores. Kotler (2019) destaca que esses clientes são mais difíceis de agradar, mais exigentes, mais conscientes em relação aos preços, sendo mais inteligentes, perdoam menos e são abordados por mais concorrentes com ofertas equivalentes ou superiores.

Para Grönroos (2009), uma empresa deve buscar enxergar o cliente como um parceiro ao invés de vê-lo somente como alguém que, de tempos em tempos, compra da empresa. Por sua vez, Las Casas (2011, p. 181) afirma que "os clientes são pessoas que sofrem muitas influências, todas ao mesmo tempo". Logo, as empresas devem estar preparadas para entender o que o cliente quer. Dessa forma, o desafio da empresa está em reter os seus clientes por mais tempo do que retém os seus produtos, mudando o foco na fabricação de produtos, para conquista e retenção de clientes. Neste sentido, uma das formas para alcançar tal feito poderia ser conceder mais benefícios aos melhores clientes, o que contribuiria também para incentivar os demais a migrar para as categorias superiores, consumindo ou comprando mais da empresa. Afinal, o retorno financeiro do cliente retido cresce ao passar do tempo. Além disso, para conquistar um novo cliente, a empresa gasta cinco vezes mais do que para conservá-lo (Kotler, 2000; 2003; Vavra, 1993).

Não obstante, as empresas costumam investir mais em novos clientes do que na permanência de seus clientes da base. Em média, são reservados cerca de 70\% dos investimentos em marketing para a conquista de novos clientes, ainda que cerca 
de 90\% dessas receitas sejam provenientes dos clientes da base (Kotler, 2003), ou seja, "manter os clientes existentes é tão ou até mais importante do que conquistar novos", como afirma Grönroos (2009, p. 22).

Para aprimorar a experiência dos clientes, Kotler (2019) propõe que, periodicamente, os gerentes busquem, por meio de simulações de compras em sua empresa e nas concorrentes, entender como o atendimento é prestado. Empresas focadas no cliente são efetivamente competentes para construir clientes e não somente produtos, facilitando a recepção de reclamações e sugestões, alertando a empresa com situações, ainda reversíveis, evitando evasão de clientes (Kotler, 2000; 2003).

\section{Qualidade no atendimento ao cliente}

O conceito da palavra qualidade está relacionado, principalmente, a algo subjetivo, uma vez que a sua definição varia para cada indivíduo. Vários fatores, como cultura, valores, tipo de produto/serviço, desejos, entre outros, influenciam o seu significado. Por isso, segundo Grönroos (2009), tratar de qualidade sem explicar como ela é percebida pelo cliente e como pode ser melhorada, tem um valor muito restrito. Sendo assim, um produto ou um serviço terá, tão somente, a qualidade percebida pelo cliente, qualquer que seja ela.

No entendimento de Moura (1999, p. 68), "a qualidade é definida como sendo a conformidade entre o que se produz com aquilo que o cliente quer", de sorte que alcance a sua satisfação e exceda as suas perspectivas. A qualidade não se limita apenas a um produto ou serviço, mas também está relacionada à forma como o cliente é atendido. Produtos e serviços com rigoroso grau de qualidade não são suficientes para satisfazer o cliente, caso ele tenha um tratamento inadequado por parte dos funcionários.

Na visão de Zenone (2010), não são as organizações que definem o grau de qualidade de um produto ou serviço, mas o mercado, o seu consumidor final. Lopes Filho (2006) acrescenta ainda que os clientes adquirem a concepção de qualidade a partir de experiências de compras e nas avaliações pós-compra.

No entanto, contrapondo a opinião de Lopes Filho, Grönroos (2009) sublinha que, embora a qualidade seja percebida de forma subjetiva, não são apenas experiências que influenciam na avaliação do cliente acerca da qualidade. Em relação ao atendimento ao cliente, a qualidade deve ser compreendida como a maneira e a habilidade das organizações em satisfazer as suas necessidades quanto empresa, como também a de empregar de forma eficiente ferramentas que agradem ao seu público.

A qualidade no atendimento deve pertencer à cultura organizacional da empresa e esta deve estar atenta às modificações relacionadas às expectativas e às exigências dos clientes (Zenone, 2010), não se restringindo, apenas, em tratar bem o cliente, pois este demanda uma necessidade específica, criando expectativas próprias do atendimento, sendo imprescindível que as empresas tenham conhecimento dessas expectativas para atendê-las da melhor maneira possível, dando aos clientes a concepção da qualidade do produto/serviço ofertado.

\section{Qualidade no serviço}

Atualmente, aborda-se muito a grande importância em oferecer ao cliente serviço de qualidade, que constitui um dos itens para conseguir a satisfação plena do cliente e, com vistas para alcançar esse objetivo, o segredo está em a empresa concentrar-se profundamente nas necessidades e nos desejos do cliente, ou seja, criando serviços que atendam ou excedam as suas expectativas. Nesse sentido, a qualidade no serviço ofertado contribui para que as organizações alcancem os resultados almejados e possibilita a satisfação dos clientes, com isso a sua permanência no mercado (Fernandes et al., 2019; Ferreira et al., 2020; Vilella et al., 2019).

Grönroos (2009, p. 64) conceitua serviços como "uma série de processos cuja produção e consumo não podem ser separados", tendo, quase sempre, atuação direta do cliente durante o seu desenvolvimento e realização. Las Casas (2011) afirma que, para que um serviço gere satisfação e percepção de qualidade ao cliente, a empresa precisa administrar bem as 
expectativas geradas pelos vendedores do serviço, pelas experiências já vividas, inclusive com outras empresas, ou até mesmo com o ponto de vista de outro cliente. Caso o serviço prestado tenha alcançado a sua expectativa, o cliente ficará satisfeito. Do contrário, gerará insatisfação.

Ainda segundo Las Casas (2011), os vendedores devem evitar propagandas exageradas de seus serviços, em caso de não refletirem a verdade, a fim de não provocarem insatisfações por superestimarem as suas expectativas. Enfatiza, também, que, ao prometer qualidade na entrega de determinado serviço, o cliente deve percebê-lo.

Para Kotler e Keller (2019), quanto maior a qualidade de um serviço, maior será a satisfação dos clientes, podendo atribuir preços mais elevados aos seus serviços, com menores custos. Ainda segundo Kotler e Keller (2019), a lucratividade de uma empresa está relacionada ao nível de satisfação de seus clientes e a qualidade de seus serviços.

\section{Qualidade no atendimento bancário}

Segundo o Relatório de Cidadania Financeira de 2018 do Banco Central do Brasil, publicado em 18 de janeiro de 2019, 86,5\% dos brasileiros acima de 15 anos possuem conta bancária. Em 2017, o Brasil possuía mais de 140 (cento e quarenta) milhões de pessoas com algum tipo de conta, seja de depósito, poupança ou de investimento. O relatório aponta que esses números, entre 2015 e 2017, ficaram estáveis. Por conseguinte, a qualidade de atendimento no âmbito financeiro passou a ser tratada com mais seriedade pelos bancos, que começaram a investir mais em novas alternativas de atendimento ao consumidor e, sobretudo, no processamento de informações, ou seja, investimento em novas tecnologias.

Atualmente, além do atendimento presencial, as instituições financeiras oferecem uma gama de outros serviços, objetivando melhorar ainda mais o seu relacionamento com os consumidores, como: serviços de atendimento ao cliente 24 horas, ouvidoria, autoatendimento, atendimento em canais alternativos, Internet Banking e, não menos importante, o Mobile Banking. $\mathrm{O}$ atendimento dos funcionários, a identidade visual das agências e a condução dos processos de crédito transmitem expectativas aos clientes em relação aos serviços. A satisfação está diretamente ligada ao atendimento dos desejos dos clientes, gerando frustrações e descontentamento quando não atingidos ou quando os canais tecnológicos (autoatendimento, Internet Banking, Mobile Banking) não funcionam adequadamente.

Segundo Kotler (2003, p. 7), "a qualidade começa com as necessidades do cliente e termina com sua satisfação". Portanto, apesar dos investimentos tecnológicos e das maiores facilidades oferecidas ao cliente, esse segmento ainda não tem fornecido a qualidade no atendimento aspirada pelo consumidor. Por seu turno, considerando que essas expectativas vêm se acentuando com o tempo, não as atender, no nível esperado, pode resultar em grandes prejuízos.

\section{Satisfação dos clientes}

De acordo com Kotler e Keller (2019, p. 142) a satisfação é: [...] a sensação de prazer ou despontamento resultante da comparação entre o desempenho percebido de um produto e as expectativas do comprador. Se desempenho não alcançar as expectativas, o cliente ficará insatisfeito. Se alcançá-las ficará satisfeito. Se o desempenho for além das expectativas, o cliente ficará altamente satisfeito ou encantando. Na concepção de Zeithaml e Bitner (2014, p. 66) as expectativas dos clientes "são crenças a respeito da execução do serviço que funcionam como padrões ou pontos de referência com relação ao qual o desempenho é julgado". Logo, a satisfação do consumidor em relação a uma compra dá-se através do desempenho positivo de suas expectativas.

No entendimento de Mattar (2011), para alcançar a satisfação do consumidor, faz-se imprescindível que a empresa procure atender a satisfação em relação ao produto/serviço e, em seguida, satisfazer outras necessidades não concernentes ao produto/serviço adquirido, como: Conveniência, serviço, entrega, escolha, contexto de compra/uso, relações do 
comprador/vendedor, financiamento, informação e garantias. Nesse sentido, Fernandes et al., (2019) e França et al., (2021) destacam que o meio mais eficaz para fidelizar o cliente é através da satisfação.

Kotler (2000, p. 63) afirma que "uma empresa inteligente cria um alto nível de satisfação de funcionários, que leva a um esforço maior, que leva a produtos e atendimento de melhor qualidade, que criam maior satisfação de clientes, que leva a negócios mais regulares, que levam a maiores taxas de crescimento e lucro, que levam a um alto nível de satisfação de acionistas, que leva a mais investimentos e assim por diante". Esse é o círculo virtuoso que significa lucros e crescimento. Clientes simplesmente satisfeitos são propensos a mudar de fornecedor caso surjam melhores ofertas. Por outro lado, clientes plenamente satisfeitos, além de permanecerem na empresa, divulgam-na para terceiros, possibilitando a aquisição de novos clientes, refletindo-se num incremento às vendas, além de contribuir para a redução de gastos na conquista de novos clientes, gerando um efeito multiplicador e um alto nível de fidelidade do cliente (Kotler, 2000; Las Casas, 2011).

Toda empresa que almeja alcançar um alto grau de fidelidade precisa oferecer um grande valor para o cliente. Afinal, conforme Kotler (2003, p. 203), "quanto mais alta a satisfação dos clientes, maior o grau de retenção". Dessa forma, quando uma empresa atinge índices elevados de satisfação, costuma divulgar tal feito para o seu público-alvo. Empresas que prezam por seus clientes e por seu valor no mercado devem realizar avaliações constantes para medir e acompanhar o nível de satisfação de seus clientes. Além disso, devem também avaliar a performance e a satisfação dos clientes quanto ao seus concorrentes.

Para Kotler (2019), reduzir preços ou ampliar serviços poderá contribuir para uma maior satisfação do cliente, porém, a empresa deverá abreviar a sua margem de lucratividade, o que, nem sempre, será vantajoso para o seu negócio. Existem clientes que, mesmo satisfeitos e sabendo que a empresa fará o máximo para atendê-los, em uma eventual pesquisa de satisfação, costumam responder negativamente, reduzindo a percepção de qualidade na entrega de produtos/serviços da empresa (Kotler, 2019).

Muitas organizações priorizam a participação no mercado em detrimento da satisfação do cliente. Na visão de Kotler (2003, p. 203), "a participação no mercado é indicador retrospectivo; a satisfação dos clientes é um indicador prospectivo". Enfatiza ainda que, caso o nível de satisfação dos clientes caia em declínio, começará um desgaste da participação no mercado.

Embora um cliente considere-se satisfeito com determinada empresa, não quer dizer que ele ficará fidelizado para sempre. Os clientes estão em busca de empresas que possam proporcionar maiores valores e, portanto, maior satisfação, sendo fundamental para a permanência do relacionamento que se cative mais do que os concorrentes. "Se esse relacionamento não for satisfatório para o cliente, a troca de valor por dinheiro cessa" (Grönroos, 2009, p. 23), ensejando possíveis perdas de clientes. Em uma de suas afirmações, de forma singular, Kotler (2003, p. 204) assegura que "o objetivo das empresas deve consistir em encantar os clientes, em vez de apenas satisfazê-los", sustentando que, caso atinjam esse propósito, a qualidade transformar-se-á em padrão.

Diante do exposto, a questão que norteia este estudo é qual a satisfação dos clientes com o atendimento disponibilizado pelo Banco X numa cidade do interior baiano? cujo objetivo foi compreender a satisfação dos clientes com o atendimento disponibilizado pelo Banco X numa cidade do interior baiano, através de um estudo qualitativo.

\section{Metodologia}

Este estudo enquadra-se na abordagem qualitativa, descritiva, do tipo pesquisa de campo. Segundo Creswell (2021, p. 186) "a pesquisa qualitativa é fundamentalmente interpretativa", devendo o investigador realizar uma análise dos dados pesquisados de forma indutiva. A abordagem descritiva, conforme Gil (2019, p. 28), "tem por objetivo levantar as opiniões, atitudes e crenças de uma população". Já para Lakatos e Marconi (2017, p. 186), a pesquisa de campo busca "fatos e fenômenos tal como ocorrem espontaneamente" no ambiente natural. 
Utilizamos uma entrevista aberta com o seguinte roteiro: Relate-nos algumas de suas experiências (positivas e negativas) com o atendimento do Banco X. Fale-nos sobre as suas vivências sobre a qualidade dos serviços prestados pelo Banco. Relate-nos algumas facilidades e dificuldades no atendimento pela Agência. Conte-nos sobre os canais de serviços alternativos de atendimento bancário que o senhor utiliza. Fale-nos sobre a sua satisfação com o atendimento do Banco X prestado ao senhor como cliente.

Os dados foram coletados por meio de uma entrevista aberta aplicada pelo primeiro pesquisador, durante o mês de fevereiro de 2019, com durações aproximadas de 15 a 20 minutos, realizadas no local de trabalho dos clientes, conforme combinação prévia. Tal meio justifica-se por permitir uma maior maleabilidade, uma vez que o entrevistador pode elucidar dúvidas quanto às perguntas, além de permitir obter dados minuciosos relativos aos hábitos dos entrevistados e às particularidades da vida social (Minayo, 2021).

Colaboraram com a entrevista 13 clientes, escolhidos intencionalmente, que, para manter o sigilo, anonimato e confidencialidade dos participantes, conforme determina a Resolução 510/16 do Ministério da Saúde (Brasil,2016), assinaram um Termo de Consentimento Livre e Esclarecido (TCLE). As entrevistas foram codificadas em C1, C2, C3, C4, C5, C6, C7, C8, C9, C10, C11, C12 e C13. A idade dos participantes varia de 28 a 60 anos, sendo oito do sexo feminino e cinco do sexo masculino e que possuem de dois a 33 anos de relacionamento com a agência.

O escrutínio dos dados deu-se por meio da análise de conteúdo por categorias temáticas que, conforme Bardin (2011) visa desvelar o conteúdo das mensagens explicitas e implícitas. Na pré-análise, fizemos a transcrição do material e leitura flutuante. Na segunda fase, fizemos a exploração do material: no processo de codificação, o critério de recorte das unidades de registro foi pelo tema, e das unidades de contexto foi pelo parágrafo. O critério de categorização das informações foi o semântico. Na terceira fase da análise de conteúdo, o tratamento dos dados, fizemos a inferência e discussão. Destacamos que o método de análise adotado foi indutivo, ou seja a posteriori, partimos das informações coletadas para a codificação e categorização e finalmente as abstrações.

\section{Resultados e Discussão}

Com base nos dados coletados e para responder a questão da pesquisa: qual a satisfação dos clientes com o atendimento disponibilizado pelo Banco X numa cidade do interior baiano. Além de cumprir o objetivo de compreender a satisfação dos clientes com o atendimento disponibilizado pelo Banco X numa cidade do interior baiano realizamos a análise de conteúdo temática dos dados, os quais foram agrupadas em quatro categorias temáticas: Experiências e vivências dos clientes; Facilidades e dificuldades no atendimento; Canais de serviços alternativos; e Satisfação geral do cliente.

\section{Experiências e vivências dos clientes}

As experiências e as vivências positivas dos clientes impactam em sua satisfação com o atendimento na agência bancária. Sendo assim, destacamos alguns excertos das entrevistas: "eu acho que as pessoas me atendem super bem", relata C7. Do mesmo modo, C2 acrescenta "A casa em que moro hoje, na época foi um plano que fiz porque o gerente da agência me aconselhou e foi um dos melhores investimentos". Ainda em relação às experiências satisfatórias outro depoente acrescenta que "certo momento, eu quitei um contrato que eu tinha lá de veículo e o gravame baixou rápido. Foi rápido, foi bem ágil, foi tudo certo. Então, como experiência ou um case de atendimento, vou relatar esta quitação, deste veículo. Agilidade de liberação de gravame" (C5).

Pelos relatos dos entrevistados, percebemos que o tratamento cortês encanta um cliente e, por outro lado, observamos que a realização do "sonho da casa própria" foi devido a um serviço oferecido pelo banco. Neste sentido, Cobra (2018, p. 16) 
enfatiza que "manter os clientes satisfeitos não basta, ou seja, não se mantêm clientes apenas satisfeitos. É preciso encantá-los, ou melhor, é preciso surpreendê-los".

Em contrapartida, as experiências desagradáveis impactam negativamente na satisfação do cliente como relata C3 ao sustentar que se trata da "pior agência bancária em infraestrutura da cidade" e ainda conclui que "é muito comum início e fim de mês, época de pagamentos, a agência se transformar literalmente na barca do inferno, com tanta gente sem condições dignas de atendimento". Dessa forma, o cliente evidencia a sua insatisfação.

Para que uma empresa possa conquistar clientes, segundo Kotler (2019), é necessário produzir um atendimento superior e melhor satisfazer as exigências do cliente. Neste sentido, $\mathrm{C} 1$ completa: "Em meu celular, tenho instalado o aplicativo do Banco X, que me facilita resolver grande parte das movimentações bancárias que preciso. No que diz respeito a necessidade de resolver algo interno, sei quem procurar". Pelos relatos dos entrevistados, percebemos que as experiências e as vivências de cada cliente são bastante particulares, de forma que "ao consumidor não é suficiente prestar bons serviços. Ele deve perceber o fato" (Las Casas, 2011, p. 40). Dessa maneira, ao gerar expectativa ao cliente a empresa tem a responsabilidade de fazê-lo notar em sua consumação.

\section{Facilidades e dificuldades no atendimento}

Zenone (2011, p. 163) evidencia que "uma das estratégias de competitividade na gestão moderna é sem dúvida oferecer um atendimento de qualidade e conquistar a fidelização dos seus clientes". Para tanto, C13 confirmou a "rapidez do funcionário em me atender quando solicitei para baixar e validar o aplicativo do [...] [Banco X]", como umas das facilidades no atendimento do banco. Nessa mesma linha, $\mathrm{C} 2$ ratificou a afirmação de $\mathrm{C} 13$, afirmando que "sempre que necessito tenho muita facilidade em ser atendido [...]. Consigo sempre resolver tudo que preciso", também como uma das facilidades do banco.

Entretanto, alguns clientes enfatizaram dificuldades no atendimento a exemplo da lotação da agência no período de pagamento de aposentados e funcionários da prefeitura da cidade, conforme afirmam C12 e C7, respectivamente: "acho desumano o atendimento no início do mês" e "a agência lotada no dia de pagamento de determinados clientes". Ademais C1 acrescenta que "o quadro de funcionários parece não ser suficiente para atendê-los. O banco fica lotado". Para Zenone (2010, p. 57), "o relacionamento é construído por meio de uma série de interações que acontecem entre empresas e clientes", devendo, portanto, evitar-se gerar descontentamentos ao cliente afim de obstar evasão destes.

\section{Canais de serviços alternativos}

Além de reduzir custos operacionais, os canais de serviços alternativos, aos olhos dos clientes, são vistos como facilitadores no relacionamento com o banco, porém, "nem todas as tecnologias de autoatendimento melhoram a qualidade do serviço, mas têm o potencial de tornar as transações de atendimento mais precisas, convenientes e rápidas", como reconhecem Kotler e Keller (2019, p. 412).

De acordo com um dos entrevistados: "o [...] [Banco X] precisa melhorar os serviços com os caixas eletrônicos, pois sempre estão em manutenção" (C10) e C12: "caixa eletrônico, razoável (não atende a nossa necessidade)", bem como de outros entrevistados, resta clara a insatisfação com esse serviço de autoatendimento e, como enfatiza Las Casas (2011, p. 297), "os serviços bem feitos geram satisfação aos clientes atendidos", destacando, portanto, deficiência no serviço ofertado pela agência.

Por outro lado, serviços como o Internet Banking e [...] Banco X Celular foram bem avaliados por vários entrevistados como C5 que classificou como "maravilhoso o atendimento por canais", afirmando, inclusive, que "faço tudo pelo celular. Pago boleto, transfiro dinheiro, tudo" e C13 que apontou que "o [...] [Banco X] Celular funciona perfeitamente". Nesse sentido Las Casas (2011, p. 297) esclarece que "no setor de serviços não há nada mais importante do que diferenciar-se 
pela qualidade", seguindo um raciocínio semelhante ao de Kotler e Keller (2019), que indicam que os clientes prezam pela comodidade dos serviços, bem como pela qualidade dos produtos.

\section{Satisfação geral do cliente}

Para Kotler (2000, p. 58), um cliente pode ter diversos graus de satisfação, em que "Se o desempenho ficar abaixo dessa expectativa, o cliente ficará insatisfeito. Se o produto preencher as expectativas, ele ficará satisfeito. Se o produto exceder essas expectativas, o cliente ficará altamente satisfeito ou encantado. (Kotler, 2000, p. 58). Dessa forma, C1 considerase "satisfeita com os serviços prestados a mim. Sempre com qualidade, atenção e dedicação", contribuindo com outra afirmação de Kotler (2000, p. 58) que expõe que "um alto nível de satisfação ou encantamento cria um vínculo emocional". Da mesma forma, $\mathrm{C} 2$ ratifica a fala de $\mathrm{C} 1$, dizendo que "é um dos bancos que mais gosto, até o momento não tive decepções", demonstrando a sua satisfação com os diversos serviços prestados.

Em outro relato, C5, em relação à sua satisfação, afirma: A minha satisfação é boa, próxima de ótima em relação ao atendimento do [...] [Banco X]. A agência, não tenho nada a reclamar não. Não acho um atendimento de excelência, mas também não acho um atendimento ruim. Classifico como um atendimento bom, satisfatório, atende a demanda como cliente. Porém, outros entrevistados não tiveram a mesma percepção, como é o caso de C6 que relata que "a agilidade de alguns serviços depende da contrapartida do cliente", referindo-se a clientes que possuem propensão em adquirir outros produtos e serviços do banco ou com movimentação financeira relevante. Já C8 declarou que "já fui várias vezes reclamar mas nada muda", em relação a acordos firmados para não cobrar tarifas em sua conta.

Para $\mathrm{C} 12$, as máquinas de autoatendimento do banco poderiam ser mais eficientes, como confirma em sua fala: "não gosto do sistema eletrônico - caixas complicados, lentos - deveria processar mais rápido", expressando, mais uma vez, o problema já relatado por outros entrevistados. Ainda assim, mesmo existindo queixas de alguns serviços prestados, os clientes C1, C2, C3, C4, C5, C7, C9, C10, C11 e C13 mostraram-se satisfeitos, restando, apenas, os clientes C6, C8 e C12 que responderam que o atendimento prestado pelo banco não era satisfatório.

\section{Considerações Finais}

Para responder a questão de partida deste estudo: qual a satisfação dos clientes com o atendimento disponibilizado pelo Banco X numa cidade do interior baiano? realizamos uma pesquisa qualitativa e após análise de conteúdo os dados foram agrupados em quatro Categorias Temáticas que sintetizam a satisfação dos clientes do banco em: Experiências e vivências dos clientes; Facilidades e dificuldades no atendimento; Canais de serviços alternativos; e Satisfação geral do cliente.

O estudo evidencia que as experiências e as vivências positivas dos clientes com o atendimento na agência bancária impactam positivamente em sua satisfação, bem como as facilidades no atendimento e que os canais de serviços alternativos oferecidos pelo banco são vistos como facilitadores no relacionamento com o banco. A maioria dos entrevistados considera que a agência em destaque satisfaz as necessidades dos clientes prestando atendimento cortês e eficiente para as demandas desses clientes. Enfim, os entrevistados dão ênfase à cordialidade, à atenção e à educação dispensada pelos funcionários da agência. Evidencia também que a qualidade dos serviços prestados pelos canais alternativos como o atendimento pelo Celular e o Internet Banking são pontos em destaque maior parte dos entrevistados.

Percebemos que pequena parcela dos entrevistados acreditam que a Agência em estudo apresenta deficiências quanto ao serviço de autoatendimento prestado no caixa eletrônico, expondo lentidão, travamentos, insuficiência de manutenção e de numerário. Ainda sobre o atendimento da agência, os clientes criticaram a sua superlotação, a falta de funcionários para períodos de maior movimento, a precária infraestrutura oferecida pelo banco para suprir a demanda por atendimento em dias 
de pico - início e fim de mês - como o do pagamento de aposentados e pensionistas do INSS, bem como dos funcionários municipais, no início de cada mês.

\section{Referências}

Banco Central do Brasil. (2019). Relatório de Cidadania Financeira 2018.

Bardin, L. (2011). Análise de Conteúdo. Editora 70.

Brasil. Ministério da Saúde. (2016). Conselho Nacional de Saúde. Resolução no 510, de 7 de abril de 2016. Diário Oficial da União.

Castelli, G. (2003). Administração Hoteleira. (9a ed.), EDUCS.

Chieira, C. C. (2017). Os Determinantes da Satisfação dos Clientes Bancários. Dissertação (Dissertação em Marketing) - Universidade de Coimbra. Coimbra.

Cobra, M. H. N. (2018). Marketing Básico: uma abordagem brasileira. (4a ed.), Atlas.

Creswell, J. W. (2021). Projeto de pesquisa: métodos qualitativo, quantitativo e misto. (2a ed.), Artmed.

Dauda, S. Y., \& Lee, J. (2016). Qualidade de serviço e satisfação do cliente: uma análise conjunta para os clientes de bancos nigerianos, International Journal of Bank Marketing, 34(6), 841-867.

Fernandes, T., \& Sousa, R. B. de S. (2019). Measurement of the degree of consumer satisfaction in function of market quality indicators: a preliminary Analysis. Research, Society and Development, 8(4).

Ferreira, D. O., \& Brito, M. L. de A. (2020). Quality of care in the clothing trade: A study in the city of Currais Novos-RN. Research, Society and Development, $9(2)$.

França, P. S., Matias, M. J. A., Lima, M. de S., \& Azevedo, D. B. de. (2021). The quality of service and its influences on customer relationships in the clothing and accessories sector. Research, Society and Development, 10(4).

Gil, A. C. (2019). Métodos e técnicas de pesquisa social. (6a ed.), Atlas.

Grönroos, C. (2009). Marketing: gerenciamento e serviços. (3a ed.), Elsevier.

Kotler, P. (2019). Administração de Marketing. (10a ed.), Prentice Hall.

Kotler, P. (2003). Marketing de A a Z: 80 conceitos que todo profissional precisa saber. Elsevier.

Kotler, P., \& Keller, K. L. (2019) Administração de Marketing. (12a ed.), Pearson Prentice Hall.

Lakatos, E. M., \& Marconi, M. A. A. (2017). Fundamentos de metodologia científica. (5a ed.), Atlas.

Las Casas, A. L. (2011). Administração de marketing: conceitos, planejamento e aplicações à realidade brasileira. Atlas.

Las Casas, A. L. (2011) Marketing de serviços. (5a ed.), Atlas.

Lopes Filho, L. S. (2006). Marketing de vantagem competitiva. Saraiva.

Mattana, F. (2017). Banco do Brasil: Satisfação dos clientes pessoa física com o modelo de relacionamento digital. Dissertação (Dissertação em Gestão de Negócios) - UNISINOS.

Mattar, F. N. (2011). Administração de varejo. Elsevier.

Minayo, M. C. S. (2021). Pesquisa Social: Teoria, método e criatividade. (18a ed.), Vozes.

Moyano, C. A. M., Angnes, D. L., \& Correa, M. D. (2020) Satisfação dos clientes bancários: uma análise bibliométrica dos artigos acadêmicos publicados na última década. Revista Brasileira de Administração Científica, 11(2) 24-41.

Moura, L. R. (1997). Qualidade simplesmente total: uma abordagem simples e prática da gestão pela qualidade. Qualitymark.

Moura, J. A. M. (1999). Os frutos da qualidade. (3a ed.), Makron Books.

Santana, F. S., Ribeiro, J. X. P., \& Silva, A. R. S. (2017). Identificação do nível de satisfação dos associados Sicoob União - Agência Rio Casca-MG. Revista Interdisciplinar do Pensamento Científico, 1(3), 169-182.

Souza, A. C. A., Jesus, A. M., Gomes, J. F., Frierich, M. C., \& Santana, P. S. (2018) Internet banking: a satisfação dos usuários de uma instituição financeira. Brazilian Applied Scienc Review, 2(6), 2057-2078.

Vavra, T. G. (1993). Marketing de relacionamento: aftermarketing. (5a ed.), Atlas.

Vilela, C. N., Braga, Y. O., Silva, V. G. M., \& Castro, W. A. de. (2020). How quality management can contribute to reduce non-conformity in Carmo Do Cajuru movement industries, MG. Research, Society and Development, 9(1). 
Research, Society and Development, v. 10, n. 11, e182101118722, 2021

(CC BY 4.0) | ISSN 2525-3409 | DOI: http://dx.doi.org/10.33448/rsd-v10i11.18722

Zeithaml, V. A., \& Bitner, M. J. (2014). Marketing de serviços: a empresa com foco no cliente. (2a ed.), Bookman.

Zenone, L. C. (2010). Marketing de relacionamento. Atlas.

Zenone, L. C. (2011). Gestão estratégica de marketing. Atlas. 